have been gathered in Figure 3. To be on the safe side, general predictions based on equation (1) should be limited to the $\Delta \mathrm{a} / \Delta \mathrm{N}$ and $\Delta \mathrm{K}$ ranges shown in Figure 3. This is because some effects of the microstructure on the fatigue behaviour of metals have been observed at extremely low and at very high $\Delta \mathrm{K}$ 's, where respectively the threshold values for fatigue crack growth, $\Delta \mathrm{K}_{0}$, or the fracture toughness, $\mathrm{K}_{\mathrm{Ic}}$, are approached (12).

The electrode potential has a marked effect on the growth rate of fatigue cracks in the gold alloy when exposed to sodium chloride solution. The reduction of the crack growth rates at negative potentials and their acceleration between $-300 \mathrm{mV}$ and $+600 \mathrm{mV}$ vs. SHE are closely analogous to earlier observations with aluminium alloys and pure silver. It is hoped that further comparisons and studies of the kind presented here will clarify the mechanistic aspects of corrosion fatigue crack growth.

\section{References}

1 F. A. Peyton, 7. Am. Dent. Assoc., 1934, 21, 394-415

2 J. L. Dais and F. L. Howland, IEEE Trans. Compon. Hybrids Manuf. Technol, 1978, CHMT-1, 158-166

3 N. E. Frost, K. J. Marsh and L. P. Pool, 'Metal Fatigue', Ox ford Engineering Series, Clarendon Press, Oxford, 1974

4 L. Graf and W. Richter, Metall, 1977, 32, 1332-1338

5 W. F. Brown and J. E. Strawley, 'Plain Strain Crack Toughness Testing of High Strength Metallic Materials', ASTM Special Technical Report 410, Am. Soc. Test. Mater., Philadelphia, U.S.A., 1969

6 J. E. Strawley and B. Cross, Mater. Res, Stand., 1967, 7, 155

7 ASTM Standard E 399-74

8 M. O. Speidel, f. Mater. Technol, 1976, 7, 364-367

$9 \mathrm{M}$. O. Speidel, in 'High-Temperature Materials in Gas Turbines', Elsevier, Amsterdam, 1974

10 M. O. Speidel, M. J. Blackburn, T. R. Beck and J. A. Feeney, in 'NACE-2', Natl. Assoc. Corros. Eng., Houston, U.S.A., 1972, pp. 324-345

11 M. O. Speidel, in 'Handbook of Stress Corrosion Cracking and Corrosion Fatigue', to be published

12 M. O. Speidel and R. B. Scarlin, in 'Gefüge und Bruch', Materialkundlich-Techn. Reihe, Vol. 3, Borntraeger, Berlin, 1977, pp. 163-189

$13 \mathrm{M}$. O. Speidel, in 'Stress Corrosion Cracking and Hydrogen Embrittlement of Iron Base Alloys', NACE-5, Natl. Assoc. Corros. Eng., Houston, U.S.A., 1977

\title{
Generation of Power by Nuclear Fusion
}

\section{A PROCESS WHICH MAY INVOLVE USE OF GOLD}

The basic objective in the concentrated efforts which are currently being made to harness energy from nuclear fusion reactions and use it for generation of electric power can be stated simply. It is to establish the necessary technology for heating and compressing fusionable fuels to the point where thermonuclear reactions occur, releasing more energy than is consumed in the process. For example, if the fuel is a mixture of the hydrogen isotopes deuterium and tritium, energy may be released as follows:

$$
\mathrm{l}^{2} \mathrm{D}+1{ }^{3} \mathrm{~T} \longrightarrow 2{ }^{4} \mathrm{He}+\mathrm{n}+17.6 \mathrm{MeV}
$$

One approach to the problem is to enclose the fuel in small pellets which are made to implode by exposure either to powerful laser beams or to beams of electrons or ions generated by very high current, very high voltage pulses of electricity. In this manner the fuel is raised to the extreme temperatures and densities which are necessary to initiate the desired fusion reaction. The work is being pursued in two centres, at the Sandia Laboratories in Albuquerque, New Mexico, and at the I.V. Kurchatov Institute of Atomic Energy in Moscow.

The design of the fuel pellets is of major importance and in investigations which have been reported upon (G. Yonas, Sci. Am., I979, 239, (5), 40-5I), they have been small concentric spheres. The innermost sphere has contained the hydrogen isotope fuel and it has been surrounded (see A. Mayer and D. S. Catlett, Plat. Surf. Finish., I978, 65, (3), 42-46) by a 'pusher' sphere of pure gold, coated on the outside by an explosive 'ablator' material. When the pellets are exposed to laser, electron or ion beams, the energy of the latter is absorbed in the ablator layer, which explodes. The intermediate pusher shell then serves to compress and heat the fuel symmetrically. The latter is forced to the centre of the pellet where the temperature and pressure conditions developed are such as to ignite the fusion reaction in the fuel. In experiments at the Sandia Laboratories, loss of energy from the imploding fuel to the pusher shell has been reduced by the production of a trapped magnetic field within the pellet by discharge of a high current pulse of electric energy through a filament embedded in the pellet. In this way the final temperature attained by the fuel has been raised and the extent of the fusion reaction (as measured by the neutron yield) increased significantly.

Gold is apparently an ideal pusher material for bringing the atoms of fuel together. Not only does it prevent penetration of the pellet by the pulsed laser, electron or ion beam and so assist in confining absorption of the energy of the beam to the ablator layer, but when this ablator layer explodes, it shields the fuel in the centre of the pellet from the radiant energy associated with the explosion. Heating up and expansion of the fuel before it implodes are therefore reduced to a minimum.

It has been calculated that a laser fusion power plant of $1000 \mathrm{MW}$ capacity could consume about one million fuel pellets per day, and that these would contain about $3 \mathrm{~kg}$ of gold. Although this gold would be recoverable, an inventory of about $960 \mathrm{~kg}$ of the metal would be required for each $1000 \mathrm{MW}$ production capacity. Current indications are that an electron beam fusion power plant would be more efficient than a laser beam plant, but that it would call for considerably greater gold inventories. 